Check for updates

Cite this: Chem. Sci., 2019, 10, 7389

๑ All publication charges for this article have been paid for by the Royal Society of Chemistry

Received 26th May 2019

Accepted 15th June 2019

DOI: $10.1039 / \mathrm{c} 9 \mathrm{sc} 02558 \mathrm{~h}$

rsc.li/chemical-science

\section{Effector responsive hydroformylation catalysis $\uparrow$}

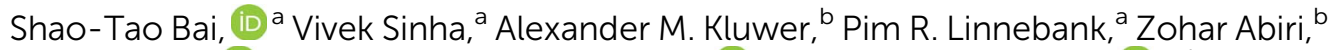
Pawet Dydio, (D) t $^{a}$ Martin Lutz, ${ }^{c}$ Bas de Bruin (iD ${ }^{a}$ and Joost N. H. Reek (D) *ab

Herein, we report a supramolecular rhodium complex that can form dimeric or monomeric Rh-species catalytically active in hydroformylation, depending on the binding of effectors within the integrated DIMreceptor. X-ray crystal structures, in situ (high-pressure (HP)) spectroscopy studies, and molecular modelling studies show that in the absence of effectors, the preferred Rh-species formed is the dimer, of which two ligands coordinate to two rhodium metals. Importantly, upon binding guest molecules, -effectors-, to the DIM-receptor under hydroformylation conditions, the monomeric Rh-active species is formed, as evidenced by a combination of in situ HP NMR and IR spectroscopy studies and molecular modelling. As the monomeric complex has different catalytic properties from the dimeric complex, we effectively generate a catalytic system of which the properties respond to the presence of effectors, reminiscent of how the properties of proteins are regulated in nature. Indeed, catalytic and kinetic experiments show that both the selectivity and activity of this supramolecular catalytic system can be influenced in the hydroformylation of 1-octene using acetate as an effector that shift the equilibrium from the dimeric to monomeric species.

\section{Introduction}

Transition metal catalysis is a key technology for the development of efficient and sustainable synthetic protocols, and as such it has been an active research field for decades. ${ }^{1}$ In order to achieve new selectivity and reactivity, most research has been devoted to catalyst development. As the catalyst properties depend strongly on the ligands that coordinate to the metal, catalyst optimization mostly relies on ligand variation. Ligand modifications that are often applied and sometimes well understood in terms of effect on the selectivity and activity displayed by the catalyst, include steric ${ }^{2}$ and electronic ${ }^{2 a, 3}$ variations and the ligand bite angle. ${ }^{4}$ Interestingly, nature uses a much larger toolbox to construct catalytic systems that are generally far more active and selective than man-made catalysts. Enzymes are nature's catalysts and they convert the substrates in the active site next to a binding site. This binding site allows substrate preorganization, and as such control of catalyst

\footnotetext{
${ }^{a}$ Homogeneous Supramolecular and Bio-inspired Catalysis, Van't Hoff Institute for Molecular Sciences (HIMS), University of Amsterdam (UvA), Science Park 904, 1098 XH Amsterdam, The Netherlands.E-mail: j.n.h.reek@uva.nl

${ }^{b}$ InCatT B.V., Science Park 904, 1098 XH Amsterdam, The Netherlands

${ }^{c}$ Bijvoet Center for Biomolecular Research, Utrecht University, The Netherlands

$\dagger$ Electronic supplementary information (ESI) available: Experimental procedures, Fig S1-S52, Scheme S1, Tables S1-S4. CCDC 1877078 and 1877079. For ESI and crystallographic data in CIF or other electronic format see DOI: 10.1039/c9sc02558h

\$ Present address: Complex Systems in Synthesis \& Catalysis, University of Strasbourg, CNRS, ISIS UMR 7006, 8 Rue Gaspard Monge, F-67000 Strasbourg, France.
}

properties via the second coordination sphere. ${ }^{5}$ Importantly, with the flourish of supramolecular approaches to build functional architectures including receptors, ${ }^{6}$ cages $^{7}$ and artificial molecular machines, ${ }^{8}$ the exploration of enzyme inspired catalysis by precise control of substrate orientation has become an active field of research. ${ }^{9}$

Another big difference between synthetic and biological systems is that enzymes in their natural environment need to operate in a complex mixture of molecules, substrates and other enzymes and their reactivity and selectivity therefore needs to be regulated. Such a regulation can be achieved by cofactor regulation, i.e. a factor that is required for the activity of the enzyme, covalent functionalization of the enzyme, such as phosphorylation, or by allosteric binding of effectors. ${ }^{5}$ The effector controlled approach is based on noncovalent binding, which is important for controlling reactivity in more complex systems by feedback loops as it can increase as well as decrease reactivity. For this reason, it is interesting to design and study catalysts that can be controlled by effectors, i.e. supramolecular binding of molecules that otherwise do not interfere with the reaction. Mirkin, Kämer and co-workers reported an orthogonal metal-ligand coordination approach to create systems based on hemilabile coordination complexes. ${ }^{\mathbf{1 0}}$ Chloride anions coordinate to the rhodium site thereby regulating the distance between two salphen complexes that operate as a binuclear Lewis acid catalyst in the "open state". Considering the interest in effector controlled transition metal catalysis, ${ }^{\mathbf{1 1}}$ we studied a supramolecular system that allows to control the activity and selectivity in hydroformylation by external factors. A new ligand coined OrthoDIMphos (L2), a regio-isomer of ParaDIMphos (L1) 


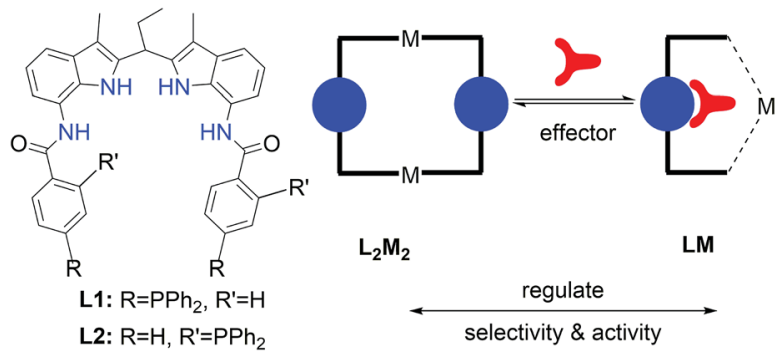

Fig. 1 The general concept of supramolecular tuning of the selectivity and activity via the regulation of the monomer-dimer catalyst equilibrium using effectors base on hydrogen bonding approach (NHs of the DIM-receptor shown in blue color).

that also has a integrated binding site for carboxylate containing guests, ${ }^{12}$ forms dinuclear structures in which each ligand coordinates to two rhodium centers, even under hydroformylation conditions. By binding of a carboxylate guest molecule, the dimer breaks up to give mononuclear species only. As the monomer and dimer display different properties in alkene hydroformylation, we effectively generated an effector responsive catalyst system (Fig. 1).

\section{Results and discussion}

\section{Synthesis of ligand OrthoDIMphos (L2)}

The ligand OrthoDIMphos (L2) was prepared following the same straightforward procedure as previously reported for the synthesis of ParaDIMphos (L1)..$^{12}$ Hydrogenation of $7,7^{\prime}$-dinitro$2,2^{\prime}$-diindolomethane led to the di-amine intermediate and subsequent condensation with 2-(diphenylphosphino)benzoic acid provided the new ligand in $91 \%$ overall yield (Schemes 1 and $\mathrm{S} 3-\mathrm{S} 5 \dagger$ ). The new ligand was fully characterized by ${ }^{1} \mathrm{H},{ }^{31} \mathrm{P}$, and ${ }^{13} \mathrm{C}$ NMR spectroscopy and HR-MS.

\section{Characterization of the square planar dimeric complexes} $\left[\mathrm{Rh}(\mathrm{L} 2)(\mathrm{CO})\left(\mathrm{BF}_{4}\right)\right]_{2}$ and $[\mathrm{Rh}(\text { effector } \subset \mathbf{L} 2)(\mathrm{CO})]_{2}$ as catalyst precursor

The rhodium complex based on OrthoDIMphos (L2) was formed by mixing the ligand with $\left[\mathrm{Rh}(\mathrm{nbd})_{2} \mathrm{BF}_{4}\right]$. Bubbling $\mathrm{CO}$ through a $\mathrm{CH}_{2} \mathrm{Cl}_{2}$ solution of OrthoDIMphos (L2) and $\left[\mathrm{Rh}(\mathrm{nbd})_{2} \mathrm{BF}_{4}\right]$ (1:1 ratio) followed by slow diffusion of antisolvent (cyclohexane) resulted in the formation of yellow crystals that were suitable for X-ray diffraction. The X-ray crystal

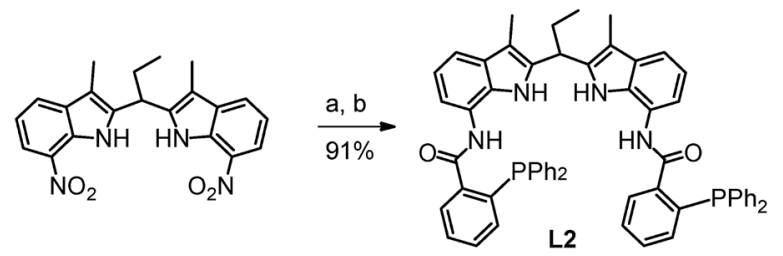

Scheme 1 Synthesis of OrthoDIMphos (L2): (a) 1 bar $\mathrm{H}_{2}, \mathrm{Pd} / \mathrm{C}, \mathrm{THF} /$ $\mathrm{MeOH}, \mathrm{RT}$; (b) 2-(diphenylphosphino)benzoic acid, 4-pyrrolidinopyridine, 4-dimethylaminopyridine, $N, N^{\prime}$-diisopropylcarbodiimide, DCM, RT.
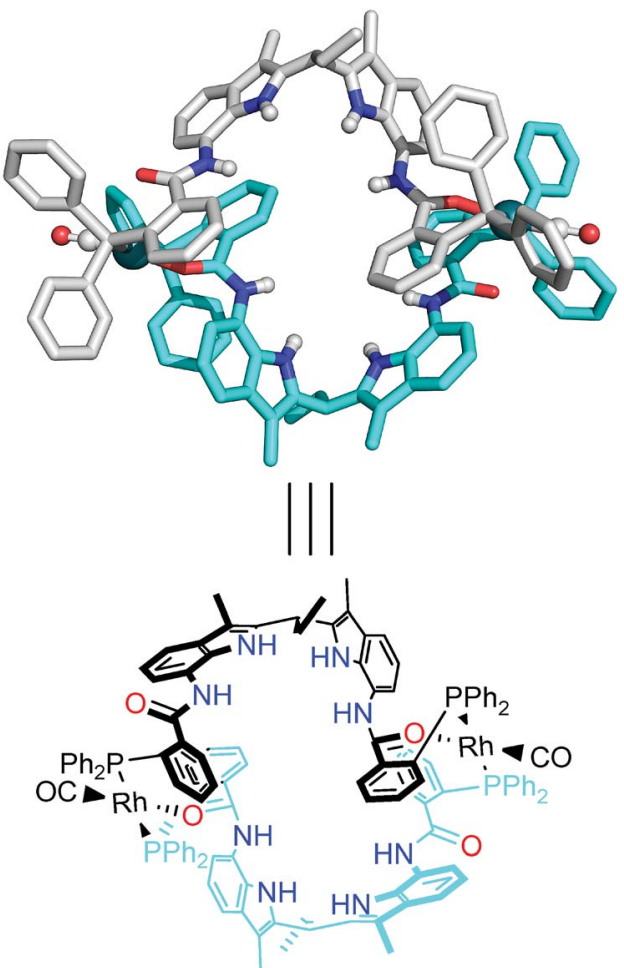

Fig. 2 X-ray crystal structure of the square planar dimeric complex $\left[\mathrm{Rh}(\mathrm{L} 2)(\mathrm{CO})\left(\mathrm{BF}_{4}\right)_{2}\right]_{2}$. Two $\mathrm{BF}_{4}{ }^{-}$counterions, hydrogen atoms (except for $\mathrm{NH}$ ) and disordered solvent molecules are omitted for clarity. For details see the ESI. $\dagger$

structure shows the formation of centrosymmetric dimeric complexes $\left(\left[\mathrm{Rh}(\mathbf{L} 2)(\mathrm{CO})\left(\mathrm{BF}_{4}\right)\right]_{2}\right.$ Fig. 2 and $\left.\mathrm{S} 1 \dagger\right)$ in which two OrthoDIMphos (L2) ligands coordinate to two rhodium atoms. The rhodium complexes have a square planar geometry, with one ligand coordinating in a $\mathrm{P}-\mathrm{O}$ chelating fashion and one with $\mathrm{P}$, with the $\mathrm{CO}$ ligand in the fourth coordination site. The two DIM-receptors of the ligands in the dimeric complex are pointing in opposite directions and all $\mathrm{NH}$ hydrogen bond donors are free to bind guest molecules. Crystals were grown in the presence of acetate as guest, and the solid state structure indeed shows a similar dimeric structure but now with acetate guest binding to the DIM pocket (for details see ESI, Fig. S16†).

The complexes were also characterized in solution by NMR spectroscopy. ${ }^{1} \mathrm{H}$ DOSY ${ }^{13}$ spectroscopy of the complexes in the absence of an effector in $\mathrm{CD}_{2} \mathrm{Cl}_{2}$ reveals a diffusion constant of $\log D$ of $-9.27 \mathrm{~m}^{2} \mathrm{~s}^{-1}$, corresponding to a hydrodynamic radius of $10.2 \AA$, in line with the formation of the dimeric Rh-complex $\left[\mathrm{Rh}(\mathbf{L} 2)(\mathrm{CO})\left(\mathrm{BF}_{4}\right)\right]_{2}$ (Fig. S2 $\dagger$ ). Additional ${ }^{31} \mathrm{P}\left\{{ }^{1} \mathrm{H}\right\}$ (a doublet at $32.94 \mathrm{ppm}, J_{\mathrm{Rh}-\mathrm{P}}=167.8 \mathrm{~Hz}$ ) and ${ }^{1} \mathrm{H}$ NMR spectroscopy show the formation of one single dimeric species (the indole- $\mathrm{NH}$ and amide-NH signals at $9.05 \mathrm{ppm}$ and $8.89 \mathrm{ppm}$ with $1: 1$ ratio), and the presence of a single set of signals indicates a fast exchange of the two ligands coordinating to $\mathrm{Rh}$ on the NMR time scale (Fig. S3-S12†).

NMR titration studies in $\mathrm{CD}_{2} \mathrm{Cl}_{2}$ using the dimeric Rhcomplexes $\left[\mathrm{Rh}(\mathbf{L} 2)(\mathrm{CO})\left(\mathrm{BF}_{4}\right)\right]_{2}$ as the host and tetrabutylammonium benzoate as the guest show that the association 
constant for benzoate to the DIM-receptor is higher than $10^{5}$ $\mathrm{M}^{-1}$, similar to that of the previously reported monomeric ParaDIMphos(L1)-Rh complex ${ }^{\mathbf{1 2}}$ (Fig. S13 and S14 $\dagger$ ). ${ }^{1} \mathrm{H}$ DOSY spectroscopy shows that the complex with guests bound has a similar diffusion constant of $\log D$ of $-9.30 \mathrm{~m}^{2} \mathrm{~s}^{-1}$ as the free analogue, indicating that the dimer structure of the precursor $\left[\mathrm{Rh}(\mathbf{L} 2)(\mathrm{CO})\left(\mathrm{BF}_{4}\right)\right]_{2}$ stays intact when benzoate guests bind to the DIM-receptors (Fig. S15†). ${ }^{14}$

\section{Characterization of the active species under hydroformylation conditions}

In order to characterize the rhodium complex under hydroformylation conditions, we performed in situ HP IR and NMR experiments. For this purpose, a 1:1 mixture of OrthoDIMphos (L2) and $\left[\mathrm{Rh}(\mathrm{acac})(\mathrm{CO})_{2}\right]$ was mixed in $\mathrm{CD}_{2} \mathrm{Cl}_{2}$, and pressurized with 7 bar $\mathrm{CO} / \mathrm{H}_{2}(1: 1)$. Upon incubation of the sample

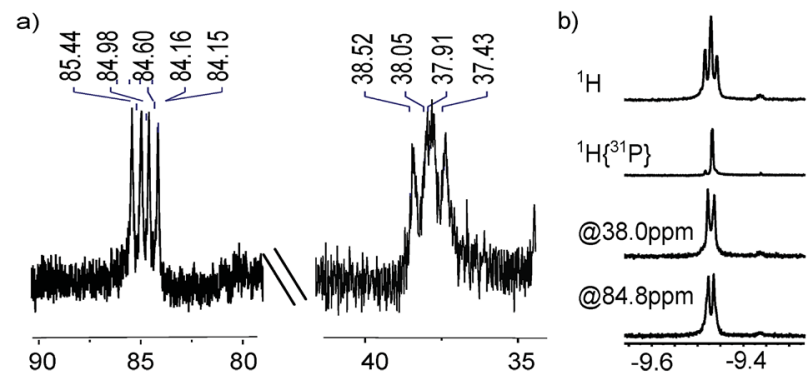

c)
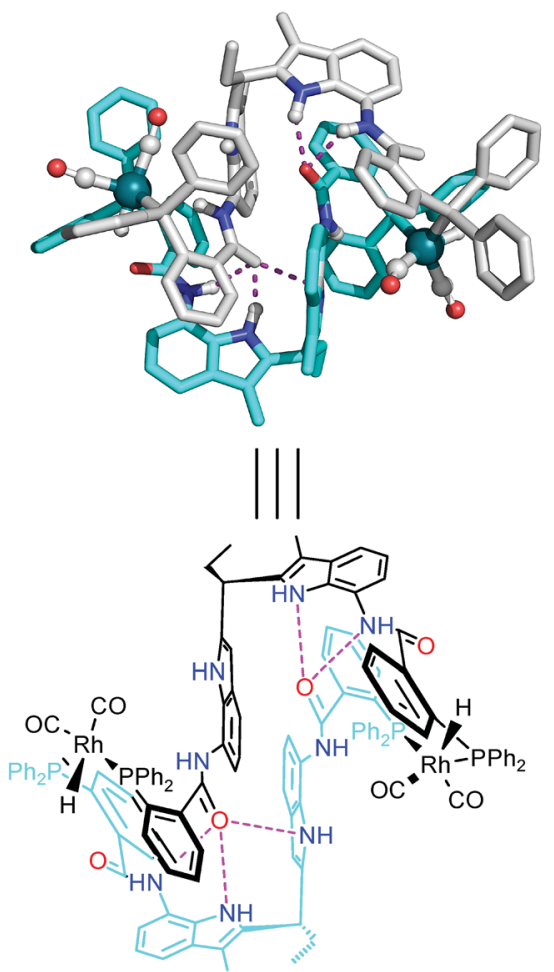

$\left[\mathrm{Rh}(\mathbf{L} 2)(\mathrm{CO})_{2} \mathrm{H}_{2}\right.$ (dimer ee-ee isomer)

Fig. 3 In situ characterization of the major dimer rhodium complex. (a) ${ }^{31} \mathrm{P}\left\{{ }^{1} \mathrm{H}\right\}$ NMR; (b) $\mathrm{HP}{ }^{1} \mathrm{H},{ }^{1} \mathrm{H}\left\{{ }^{31} \mathrm{P}\right\}$ and ${ }^{1} \mathrm{H}\left\{\mathrm{sel}{ }^{31} \mathrm{P}\right\}$ NMR of the Rhhydride region; (c) DFT model of the neutral dimeric species $D$ with ee-ee conformation (hydrogen bonds shown by purple dots). at ambient temperature for about $10 \mathrm{~min}$, complete formation of the active species was observed by ${ }^{1} \mathrm{H}$ HP NMR spectroscopy. Various NMR experiments were performed to identify the rhodium complex formed under these conditions (Fig. 3, 4 and S17-S28†). The diffusion constant of the Rh-species under syngas conditions is comparable to that of the dimeric Rhcomplex $\left[\mathrm{Rh}(\mathbf{L} 2)(\mathrm{CO})\left(\mathrm{BF}_{4}\right)\right]_{2}\left(\log D\right.$ of $-9.27 v s .-9.20 \mathrm{~m}^{2} \mathrm{~s}^{-1}$, Fig. S17 $\dagger$ ), indicating that also under actual hydroformylation conditions a dimeric species is formed. Further NMR experimental data are also in line with a dimeric structure in which two ligands coordinate to two rhodium metals. The ${ }^{31} \mathrm{P}\left\{{ }^{1} \mathrm{H}\right\}$ NMR spectra shows two doublets of doublets at $84.8 \mathrm{ppm}$ $\left(J_{\mathrm{Rh}-\mathrm{P}, \mathrm{P}-\mathrm{P}}=167.8,90.9 \mathrm{~Hz}\right)$ and $38.0 \mathrm{ppm}\left(J_{\mathrm{Rh}-\mathrm{P}, \mathrm{P}-\mathrm{P}}=124.4,93.5\right.$ $\mathrm{Hz}$ ), indicating that the two phosphorus atoms coordinated to the Rh center are inequivalent on the NMR time scale (Fig. 3a, $\mathrm{S} 18$ and $\mathrm{S} 19 \dagger)$. Moreover, phosphorus decoupled $\left({ }^{1} \mathrm{H}\left\{{ }^{31} \mathrm{P}\right\}\right)$ and selective phosphorus decoupled $\left({ }^{1} \mathrm{H}\left\{\mathrm{sel}^{31} \mathrm{P}\right\}\right)$ NMR spectroscopy reveals that the Rh-hydride couples to both phosphorus atoms at $84.8 \mathrm{ppm}$ and $38.0 \mathrm{ppm}$ with coupling constant of $29 \mathrm{~Hz}$ and $20 \mathrm{~Hz}$, respectively (Fig. $3 \mathrm{~b}, \mathrm{~S} 20$ and S21†). The

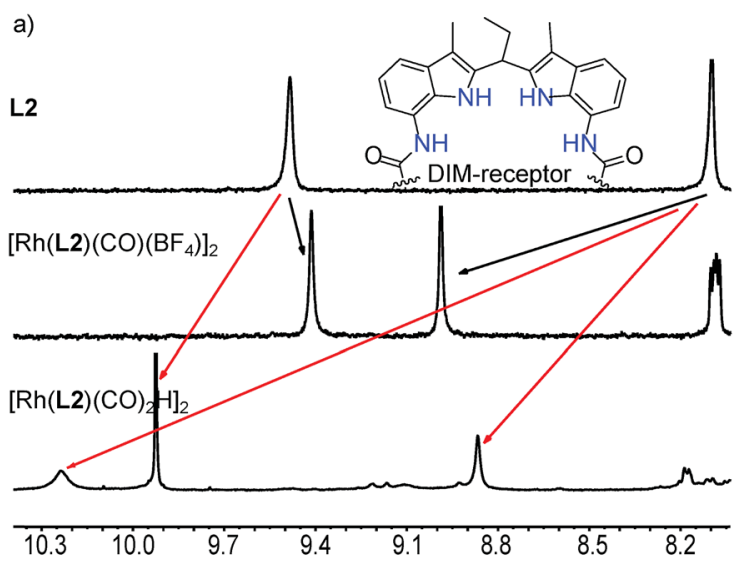

b)

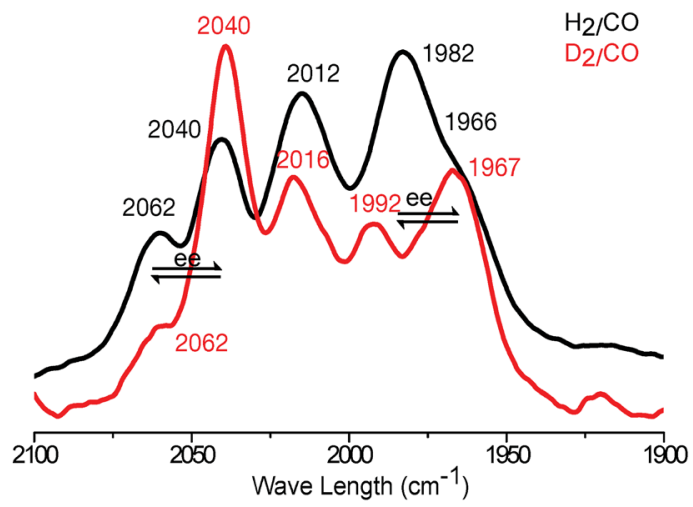

Fig. 4 In situ characterization of the major dimer Rh-active species. (a) ${ }^{1} \mathrm{H}$ NMR of NH region of the DIM-receptor of the free ligand L2 (the upper spectra), the square planar dimeric complex $\left[\mathrm{Rh}(\mathrm{L} 2)(\mathrm{CO})\left(\mathrm{BF}_{4}\right)\right]_{2}$ (the middle spectra) and the trigonal bipyramidal dimeric active species $\left[\mathrm{Rh}(\mathrm{L} 2)_{2}(\mathrm{CO})_{2} \mathrm{H}_{2}\right.$ (the bottom spectra); (b) in situ HP IR spectra of the dimeric active species under 20 bar of syngas. The ee coordination fashion is revealed by the shifts of the IR bands of the Rh-CO when changing the apical $\mathrm{H}$ to $\mathrm{D}$. 
phosphorus-phosphorus and phosphorus-hydride coupling constants are in line with a typical coordination geometry around rhodium, which is a mixture of coordination complexes with the ligands in equatorial-equatorial (ee) and equatorialaxial (ea) coordination fashion that exchanges rapidly on the NMR timescale (vide infra). The coupling constant of the hydride with Rh is $4.6 \mathrm{~Hz}$, which is typical for these type of Rhphosphine complexes. ${ }^{12,15} \mathrm{HP}{ }^{1} \mathrm{H}$ NMR spectroscopy shows that also the DIM-receptor is no longer symmetrical $1: 2: 1$ ratio instead of $2: 2$ ratio of the $\mathrm{NH}$ proton of the DIM-receptor for the square planar complex $\left[\mathrm{Rh}(\mathbf{L} 2)(\mathrm{CO})\left(\mathrm{BF}_{4}\right)\right]_{2}$ and the monomeric complex $\left[\mathrm{Rh}(\mathbf{L 1})(\mathrm{CO})_{2} \mathrm{H}\right]$, Fig. $4 \mathrm{a}$ and $\left.\mathrm{S} 22-\mathrm{S} 24 \dagger\right)$. The distinct downfield shifts of the amide-NH and indole-NH signals of the DIM-receptors $(\Delta \delta \quad 0.58-2.27 \mathrm{ppm}$ and $1: 2: 1$ ratio) indicate that these protons are involved in hydrogen bonding. As this is not observed for the monomeric complex based on $\mathbf{L 1}$ this suggests that under hydroformylation conditions this hydrogen bonding in the DIM-receptor is important for the formation of the dimeric structure. DFT calculations of the dimeric structure also show that in the energetically most favourable conformation the amide-carbonyl group of one ligand hydrogen bonds with the DIM-receptor of the adjacent ligand within the dimer complex (Fig. 3c, structures A-D at Fig. S25†). ${ }^{16}$

At room temperature a single set of phosphorus signals was obtained, indicating fast exchange between the complexes in various coordinations modes (ee-ea, ee-ee and ea-ea) on the NMR time scale. At low temperature these exchange processes slow down, and at $-92{ }^{\circ} \mathrm{C}$, three sets of signals are observed representing these different dimeric complexes (vide supra, Fig. S26†). To further investigate the coordination geometry around rhodium in the dimeric species, HP IR experiments were carried out using $\mathrm{H}_{2} / \mathrm{CO}$ or $\mathrm{D}_{2} / \mathrm{CO}$ (both 1:1). For a monomeric complex present as a mixture of the ee and ea coordination mode, four peaks in the carbonyl region can be expected, and for monomeric species $\left[\mathrm{Rh}(\mathbf{L 1})(\mathrm{CO})_{2} \mathrm{H}\right]^{12}$ three peaks are observed as a result of overlap. For the dimer $\left[\mathrm{Rh}(\mathbf{L} 2)_{2}(\mathrm{CO})_{2} \mathrm{H}\right]_{2}$ that is present as a mixture of various coordination modes (ee-ea, ee-ee and ea-ea) five peaks in the carbonyl region can be observed, again as a result of partial overlap (Fig. 4). The intensity and peak region difference $\left(\Delta \nu 22 \text { and } 15 \mathrm{~cm}^{-1}\right)^{17}$ indicate the presence of both ee and ea coordination species, as also predicted by DFT calculations (Fig. 4b, Table S1, Fig. S25 and $29, \dagger$ vide supra).

Besides the major dimeric Rh-species, Rh-hydride signals of a minor Rh-species was observed by ${ }^{1} \mathrm{H}$ NMR (less than $10 \%$, Fig. S20, S27 and S28†). ${ }^{18}{ }^{1} \mathrm{H}$ DOSY spectroscopy shows that the signal is of a species that has a diffusion constant comparable to the monomeric ParaDIMphos-Rh complex $(\log D$ of $-9.10 v s$. $-9.13 \mathrm{~m}^{2} \mathrm{~s}^{-1}$, Fig. $\mathrm{S} 17$ and $\left.\mathrm{S} 28 \dagger\right)$, confirming that this species involves a monomeric Rh complex. VT NMR spectroscopy also shows that the monomer/dimer ratio changes in favour of the dimer at lower temperatures, indicating an enthalpy driven process in line with hydrogen bonds partaking in the dimerization process.

\section{Controlling dimer-monomer equilibrium by effector binding} under hydroformylation conditions

As the dimeric structure of the hydride species is stabilized by hydrogen bonding of the carbonyl-O groups of the ligand with the DIM-receptors, the binding of competing carboxylate containing effectors would affect the relative stability of the dimer compared to the monomeric Rh-species. We therefore investigated the effect of the binding of effectors on the monomer/ dimer equilibrium (Fig. 5 and $\mathrm{S} 30-\mathrm{S} 35 \dagger$ ). For this purpose, a mixture of OrthoDIMphos (L2), $\left[\mathrm{Rh}(\right.$ acac $\left.)(\mathrm{CO})_{2}\right]$, acetic acid and triethylamine $(1: 1: 400: 400$ ratio, $[\mathrm{Rh}]=1 \mathrm{mM})$ was dissolved in $\mathrm{CH}_{2} \mathrm{Cl}_{2}$ and pressurized with 20 bar $\mathrm{CO} / \mathrm{H}_{2}(1: 1)$. In situ HP IR spectra of this mixture shows the formation of a new rhodium species that displays one broad peak in the Rhcarbonyl region $\left(1902 \mathrm{~cm}^{-1}\right)$, instead of five peaks observed for the dimeric rhodium complex. Interestingly, the IR band at $1902 \mathrm{~cm}^{-1}$ is quite unusual as the Rh-carbonyl IR bands for these type of complexes are generally found in the region of 1950-2100 $\mathrm{cm}^{-1} \mathbf{1 f}^{1 \mathbf{1 2 , 1 9}}$ This suggests strong back donation from the Rh center to the carbonyl ligands, or it may shift as a result

a)

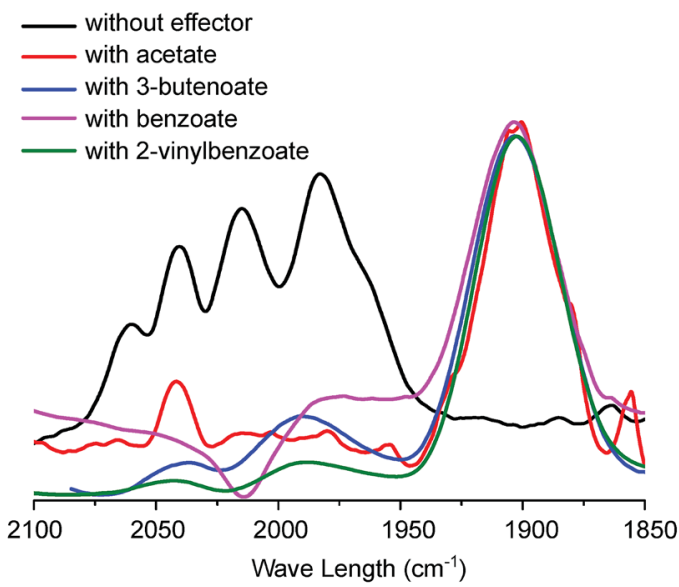

b)
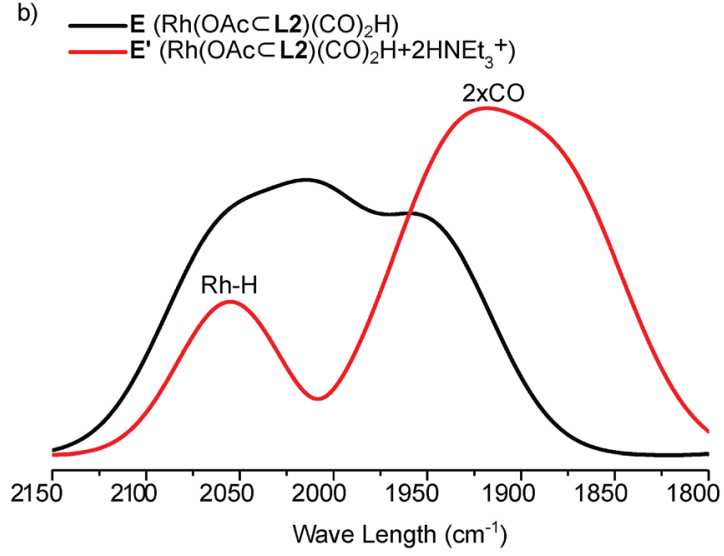

Fig. 5 In situ characterization of the monomeric Rh-active species via effector binding to the DIM-receptor. (a) In situ HP IR spectra of the monomeric Rh-species with different effectors (200 equivalents of effectors with respect to the DIM-receptor); (b) calculated IR spectra (BP86-D3/def2-SV(P)) of the active monomeric $\left[\mathrm{Rh}(\mathrm{OAC} \subset \mathrm{L} 2)(\mathrm{CO})_{2} \mathrm{H}\right]$ species with acetate as effector binding to the DIM-receptor. 
of hydrogen bonding with $\mathrm{HNEt}_{3}{ }^{+}$that is also present in solution. We therefore performed DFT (BP86-D3/def2-SV(P)) calculations to understand the experimental spectra (Fig. $5 \mathrm{~b}$ and S30-S35 $\dagger)^{20}$ The calculated IR spectra of the monomeric Rh-species $\mathbf{E}\left[\mathrm{Rh}(\mathrm{OAc} \subset \mathbf{L 2})(\mathrm{CO})_{2} \mathrm{H}\right]$ with acetate binding to the DIM-receptor shows two Rh-carbonyl and one Rh-H bands merged at $2035 \mathrm{~cm}^{-1}$. This absorption is shifted with respect to the experimentally observed band at $1902 \mathrm{~cm}^{-1}$. Instead, the calculated IR spectra of the monomeric Rh-species $\mathbf{E}^{\prime}$ $\left[\mathrm{Rh}(\mathrm{OAc} \subset \mathbf{L 2})(\mathrm{CO})_{2} \mathrm{H}\right] \cdot\left(\mathrm{HNEt}_{3}{ }^{+}\right)_{2}$, with two $\mathrm{HNEt}_{3}{ }^{+}$present that form hydrogen bonds with the Rh-CO, shows two Rh-carbonyl bands merged in a broad peak at $1900 \mathrm{~cm}^{-1}$, close to the peak found in the experiment. The $\mathrm{Rh}-\mathrm{H}$ band calculated to be at $2030 \mathrm{~cm}^{-1}$ was not observed experimentally, as is rather common for these type of rhodium(I)hydrido species. $^{\mathbf{1 e}, \mathbf{1 9}}$ Similar IR shifts were observed for complexes based on our previously reported bisphosphite DIMPhos ligands. ${ }^{12 d}$ Experiments with other effectors, such as 3-butenoate, benzoate and 2-vinyl benzoate, show the similar spectra (Fig. 5a). This shows that the equilibrium between the dimeric and monomeric species can be controlled by the binding of different carboxylate containing effectors in the DIM-receptor.

Further evidence for the ability to control the monomer/ dimer equilibrium by effector binding came from NMR spectroscopy studies (Fig. 6a and S36-S43†). The ${ }^{31} \mathrm{P}\left\{{ }^{1} \mathrm{H}\right\}$ NMR
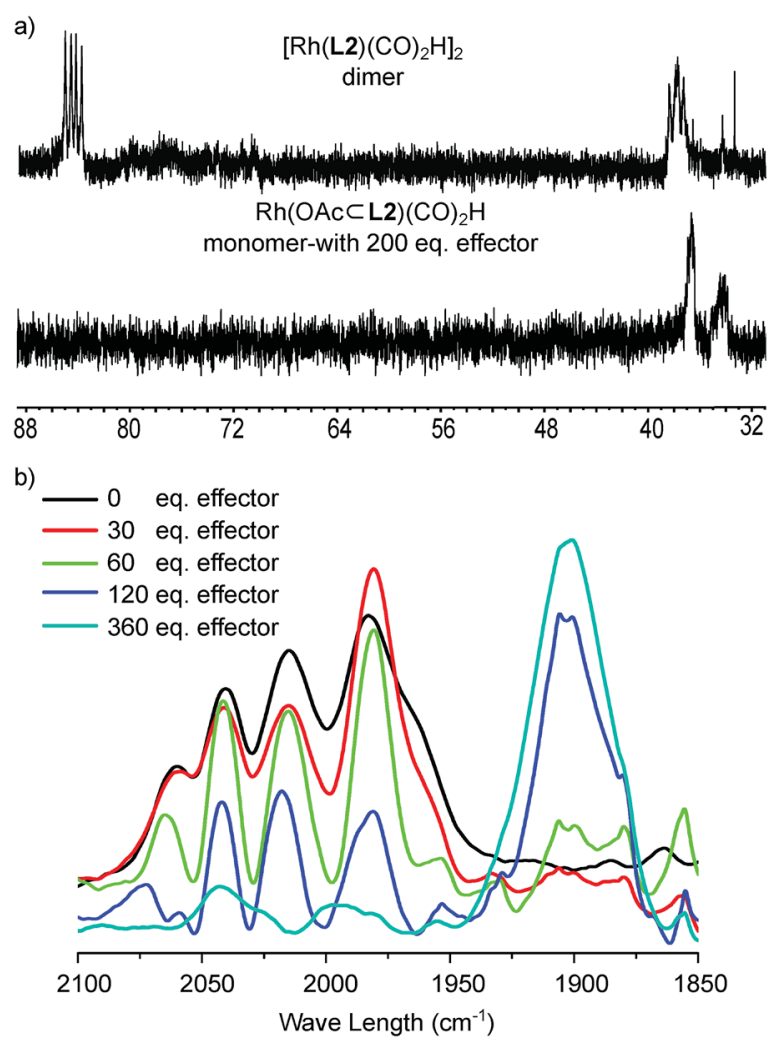

Fig. 6 In situ characterization of the monomeric Rh-active species via effector binding to the DIM-receptor. (a) ${ }^{31} \mathrm{P}\left\{{ }^{1} \mathrm{H}\right\}$ NMR spectra of the dimeric and monomeric Rh-active species; (b) in situ regulation of the equilibrium between the dimeric and monomeric Rh-active species with varying amounts of effectors. spectrum of the complex in the presence of acetate shows two broad peaks at 36.7 and $34.4 \mathrm{ppm}$ separated by $2.3 \mathrm{ppm}$, which is very different from the two doublets of doublets at 84.8 and 38.0 ppm assigned to the dimeric complexes (Fig. $6 \mathrm{a}$ and $\mathrm{S} 38 \dagger$ ), as also predicted by DFT (BP86/DZP) calculated NMR spectra ${ }^{21}$ (Fig. S39-S43†).

In order to show that the equilibrium between the dimeric and monomeric species can be regulated by the binding of an effector, we next performed a titration study monitored by in situ HP IR spectroscopy. For this experiment, the dimeric rhodium complex was prepared under hydroformylation conditions ( 20 bar $\mathrm{H}_{2} / \mathrm{CO}$ ), and subsequently various amounts of acetates as effectors (acetic acid : triethylamine, $1: 1$ ratio, 30-360 equivalents to the DIM-receptor) were injected into the HP IR autoclave under syngas pressure. As expected, the HP IR spectra show the gradual transformation with increasing amounts of acetate of the spectrum with five bands typical for the dimeric complex, to the large broad band associated to the monomeric complex (Fig. 6b). This experiment confirms that the equilibrium between the dimer and the monomer can be regulated by the binding of the effector under catalytic conditions.

To further support that this dimer-monomer equilibrium can be controlled by effector binding, the dimeric and monomeric rhodium complexes were modelled at BP86-D3/def2-SV(P) level, and the energies were computed using single point calculation at B3LYP-D3/TZVP/COSMO(DCM) level (Fig. 7, S44 and Table $\mathrm{S} 4 \dagger)$. Since the entropy is difficult to calculate accurately for large supramolecular systems, the enthalpy energy was used to compare the stability of various structures. These DFT calculations show that the dimeric rhodium complexes in ee-ee, ee-ea and ea-ea coordination fashion are 1.2$5.2 \mathrm{kcal} \mathrm{mol}^{-1}$ more stable than the monomeric complex in which the phosphorus ligands are coordinated in the ee mode (Fig. S44 $\dagger$ ). In the calculated structure of the dimeric complex the two phosphorus atoms of each ligand coordinate to two different Rh atoms, as observed in the X-ray structures of the related complexes. The two phosphorus atoms are different as only one has the carbonyl-O function partially hydrogen bonded in the DIM-receptor of the adjacent ligand (the $\mathrm{N}-\mathrm{O}$ distances of 2.937-3.035 ̊), in line with experimental observations in the NMR spectra. According to these calculations, these dimeric complexes are more stable than the monomeric analogue due to the formation of these hydrogen bonds. When acetate as effector binds to the DIM-receptor, the monomeric rhodium complex, in either ee or ea coordination mode, is more stable than the dimeric complex by ca. $25 \mathrm{kcal} \mathrm{mol}^{-1} \cdot{ }^{22}$ Thus, combined experimental and theoretical evidence shows that under hydroformylation conditions the complexes are in the dimeric form, unless a sufficient amount of acetate containing effector is present to bind to the DIM-receptor.

\section{Control over selectivity and reactivity in hydroformylation catalysis using the dimer-monomer equilibrium}

We next studied if the dimeric and monomeric complexes also display different selectivity and reactivity in the hydroformylation 


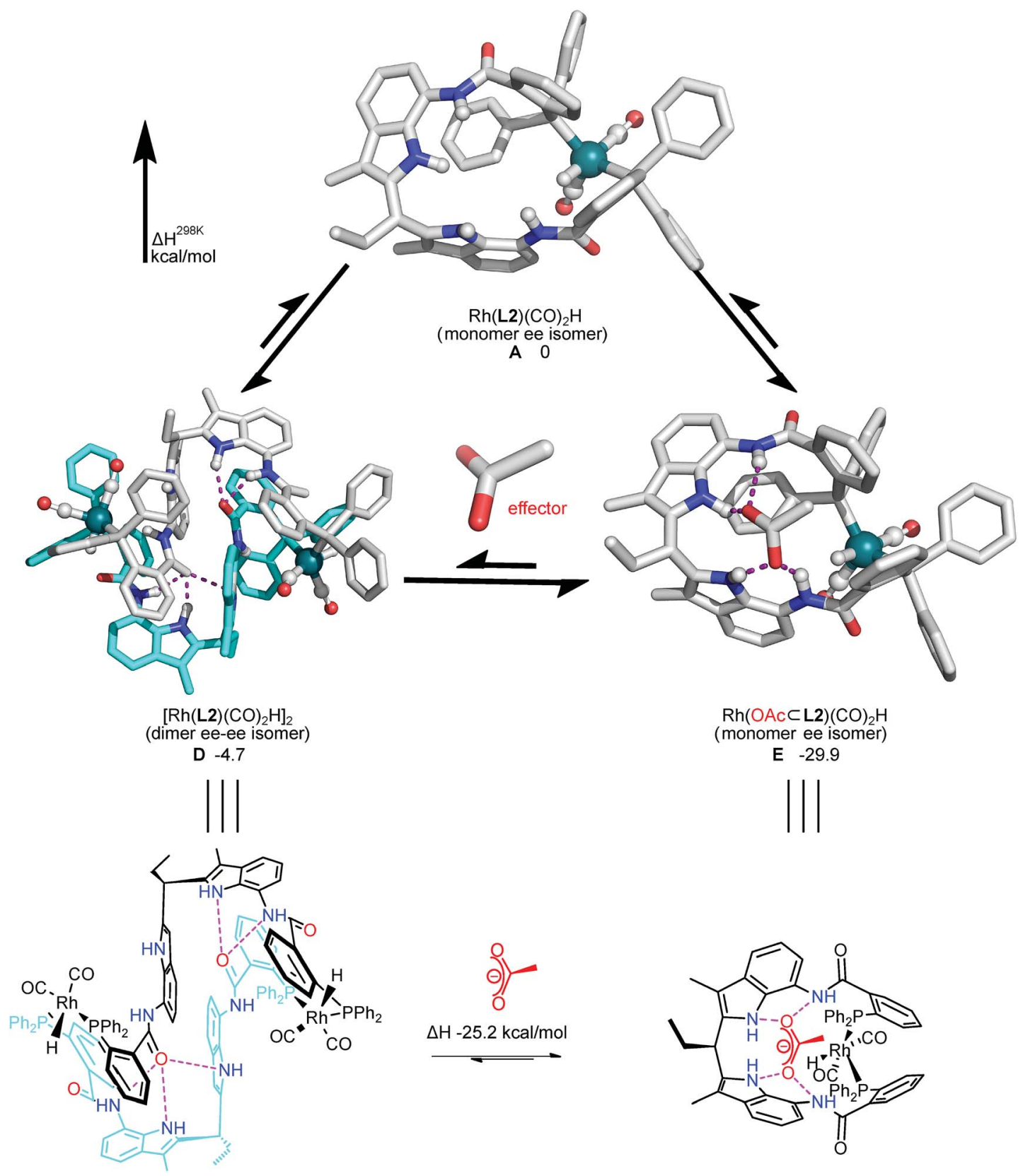

Fig. 7 DFT optimized structures of the key dimer and monomer rhodium complexes controlled by acetate binding as effector (BP86-D3/def2SV(P)//B3LYP-D3/def2-TZVP/COSMO(DCM)). The ee isomer of the monomeric trigonal bipyramidal Rh-species (A), the ee-ee isomer of the dimeric trigonal bipyramidal Rh-species (D), the ee isomer of the monomeric trigonal bipyramidal Rh-species $\left[R h(O A c \subset L 2)(C O){ }_{2} H\right]$ with acetate bound in the DIM-receptor (E). $\mathrm{H}_{298}$ : enthalpy at $298 \mathrm{~K}$ (relative to the monomeric active Rh-species (A) in kcal mol ${ }^{-1}$ ). Hydrogen bonds are shown in purple dots. The charge of the effector is -1 . Details see the ESI. $\dagger$

of 1-octene (Scheme 2, Fig. 8, 9 and S45-S48, Tables S2 and S3†). All the experiments were performed in an AMTEC SPR16 under identical conditions of pressure and temperature while

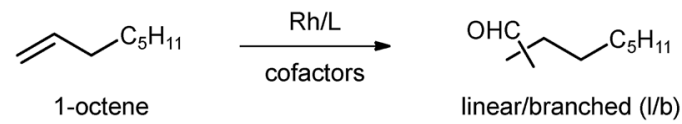

Scheme 2 Hydroformylation of 1-octene via effector controlled catalysis. recording the gas-uptake curves. The selectivity and conversion were determined by gas chromatography and NMR analysis using an internal standard. We used acetate as effector to shift the equilibrium from dimer to monomer, in order to limit the steric effects of the binding of the effector on the catalysis. ${ }^{23}$ In the absence of acetate effector, the dimeric rhodium complex converted 1-octene with a linear/branched product ratio of 4.2 (81\% linear aldehyde and $19 \%$ branched aldehyde). In the presence of the acetate effector (100-400 equivalents), the monomer rhodium complex is the dominant species present and 

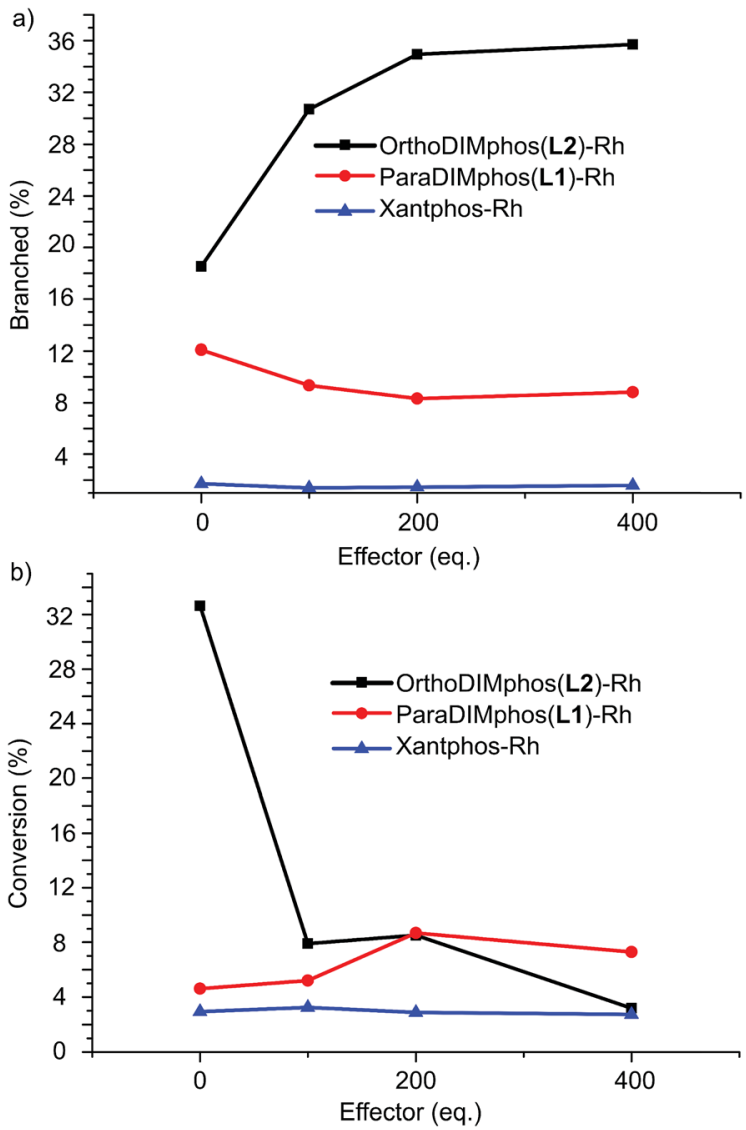

Fig. 8 (a) The selectivity and (b) conversion vs. the amounts of effectors applied in the hydroformylation of 1-octene for various catalytic systems. Reaction conditions: [substrate] $=0.6 \mathrm{M},[\mathrm{Rh}]=$ $1 \mathrm{mM}$, acetate effector (acetic acid : TEA $1: 1$ ratio, 0-0.4 M), solvent dichloromethane, 20 bar of syngas, reaction temperature $25{ }^{\circ} \mathrm{C}$, reaction time of $48 \mathrm{~h}$. The error is less than $5 \%$.

this complex converts 1-octene with a linear/branched product ratio of 1.8, which is two fold increase of the branched isomer product (19\% vs. $37 \%)$. Next to the selectivity, the reactivity displayed by the monomeric complex is also very different. The recorded gas-uptake curves have been analyzed and for the OrthoDIMphos based catalyst system, the reaction rate is about ten times faster in absence than in presence of the acetate effector, in line with the conversion (Fig. 8, 9b, c and S45-S48†). Importantly, these results reveal that the dimeric and monomeric active species display different activity and selectivity in the hydroformylation of 1-octene. Thus, the catalyst properties can be regulated by the effector binding to the DIM-receptor.

As control experiments we studied the effect of the acetate binding to the ParaDIMphos-rhodium ${ }^{12}$ catalyst, which is only present in the monomeric form (Fig. 8, Tables S2 and S3†). As expected, the presence of acetate has limited influence on the selectivity and activity ( $1 / \mathrm{b} c a$. 10, conversion $4-8 \%)$. A similar control experiment using rhodium Xantphos ${ }^{24}$ as catalyst also shows that the presence of $0-400$ equivalents of acetate does not influence the selectivity and activity $(1 / \mathrm{b} c a .60$, conversion $3 \%$, Fig. 8). In line with that, analysis of the kinetic data of the Xantphos and ParaDIMphos based rhodium complexes show
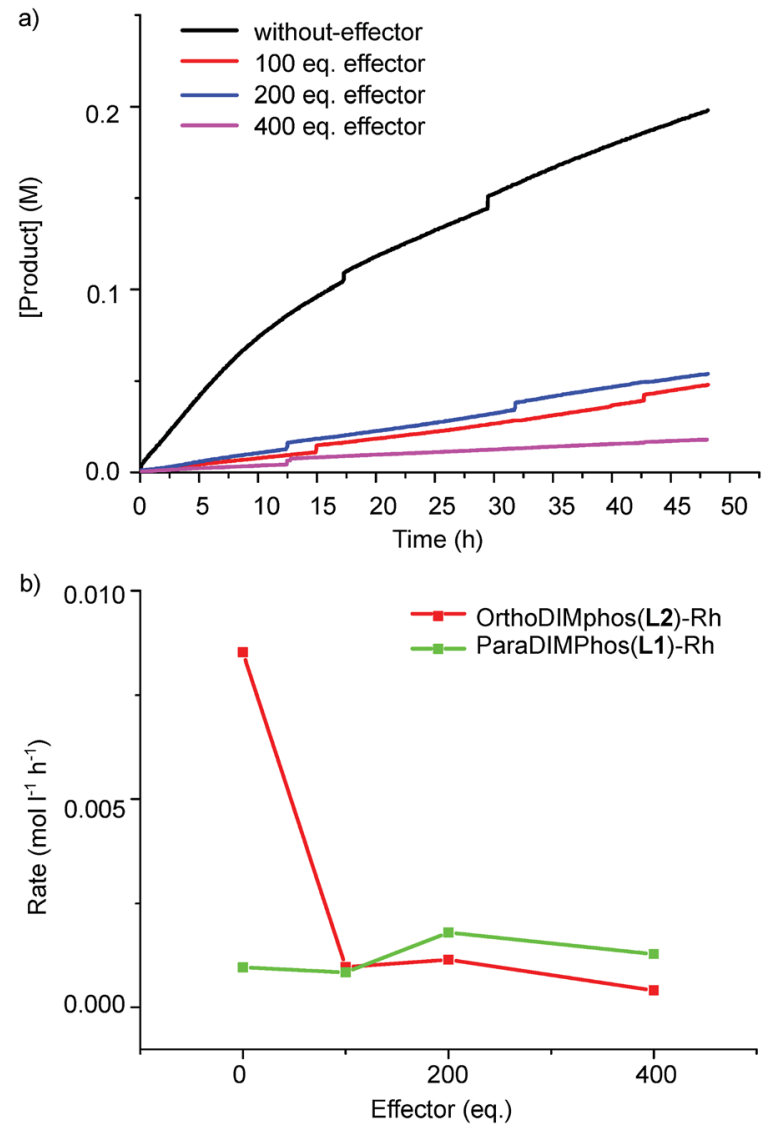

Fig. 9 (a) Aldehyde product concentration vs. time using the OrthoDIMphos-Rh catalyst system; and (b) reaction rate at $2 \%$ conversion vs. the amount of effectors. Reaction conditions: [substrate] $=0.6 \mathrm{M}$, $[\mathrm{Rh}]=1 \mathrm{mM}$, acetate effector (acetic acid : TEA $1: 1$ ratio, 0-0.4 M), solvent dichloromethane, 20 bar of syngas, reaction temperature $25{ }^{\circ} \mathrm{C}$, reaction time of $48 \mathrm{~h}$. The error is less than $5 \%$.

that the activity does not change in the presence of acetate, i.e. acetic acid and triethylamine of $1: 1$ ratio. Importantly, these control experiments also reveal that the triethylammonium carboxylate salts generated do not influence the activity and selectivity via the interaction with the catalytic center. Instead, the modification of the catalyst conformation via effector binding to the second coordination sphere plays dominated role in the regulation of the activity and selectivity. Thus, these experiments demonstrate that the OrthoDIMphos-Rh catalyst represents an unique responsive catalyst system as the activity and selectivity can be tuned by the addition of acetate as effector.

\section{Conclusions}

In this paper, we report a new ligand, OrthoDIMphos (L2), that forms dimeric complexes $[\mathrm{Rh}(\mathbf{L} 2)]_{2}$ when coordinated to rhodium, as evidenced by the two X-ray crystal structures and spectroscopic studies in solution. The dimeric structure under hydroformylation conditions is favoured by hydrogen bonding interactions between the carbonyl-O groups of the ligand and the DIM-receptors. As binding of guests competes with this 
hydrogen bonding, the presence of carboxylate containing effectors in solution results in the formation of monomeric complexes, and as such these guests are effectors that control the dimer-monomer equilibrium of these complexes. As the monomeric and dimeric complexes have different properties in the hydroformylation of 1-octene, this catalytic system represents an effector responsive hydroformylation catalyst. Both the regioselectivity and reactivity are different when the reaction is carried out with catalyst in monomeric or dimeric state ( $1 / \mathrm{b} 4.2$ to 1.8 , rate 0.008 to $0.0004 \mathrm{~mol}\left(\mathrm{l}^{-1} \mathrm{~h}^{-1}\right)$ ). As such, we demonstrate in this paper the first example of the control of the selectivity and reactivity in the hydroformylation reaction using effectors to change the active species from dimer to monomer conformation. This type of regulatory mechanism is rather common in nature, but very rare for synthetic systems. These systems can be useful for catalysis in more complex mixtures of catalysts and substrates, and experiments along these lines are currently carried out in our laboratories.

\section{Conflicts of interest}

There are no conflicts to declare.

\section{Acknowledgements}

We acknowledge Jan Meine Ernsting and Dr Andreas W. Ehlers for helping with High-Pressure NMR studies and many fruitful discussions. S.-T. Bai thanks the China Scholarship Council for a PhD fellowship (CSC student number 201506010269) and University of Amsterdam for financial support. VS and BdB thank the NWO-Shell Computational sciences for energy research initiative (project 13CSER003) and the RPA Sustainable Chemistry of the University of Amsterdam.

\section{Notes and references}

1 (a) B. Breit and L. Diab, Hydroformylation and Related Carbonylation Reactions of Alkenes, Alkynes, and Allenes, Elsevier Ltd., 2014, vol. 4; (b) P. W. N. M. van Leeuwen, R. Lazzaroni, R. Settambolo, A. Caiazzo, P. C. J. Kamer, J. N. H. Reek, C. P. Casey, G. T. Whiteker, C. Claver, S. Castillón, E. Fernández, J. Herwig, R. Fischer and P. Arnoldy, Rhodium catalyzed hydroformylation, Springer Netherlands, 1st edn, 2002; (c) M. L. Clarke and J. J. R. Frew, in Organometallic Chemistry, The Royal Society of Chemistry, 2009, vol. 35, pp. 19-46; (d) A. A. Oswald, D. E. Hendriksen, R. V Kastrup and E. J. Mozeleski, in Homogeneous Transition Metal Catalyzed Reactions, American Chemical Society, 1992, vol. 230, pp. 395-418; (e) J. Klosin and C. R. Landis, Acc. Chem. Res., 2007, 40, 12511259; (f) R. Franke, D. Selent and A. Börner, Chem. Rev., 2012, 112, 5675-5732; $(g)$ F. Agbossou, J. Carpentier and A. Mortreux, Chem. Rev., 1995, 95, 2485-2506; (h) P. C. J. Kamer, P. W. N. M. Van Leeuwen and J. N. H. Reek, Acc. Chem. Res., 2001, 34, 895-904; (i) P. W. N. M. van Leeuwen, Homogeneous Catalysis, Springer Netherlands, Dordrecht, 1st edn, 2004, vol. 30; (j) B. Breit, in Metal
Catalyzed Reductive $C-C$ Bond Formation, ed. M. J. Krische, Springer Berlin Heidelberg, Berlin, Heidelberg, Heidelberg, 2007, pp. 139-172.

2 (a) Phosphorus(III) Ligands in Homogeneous Catalysis: Design and Synthesis, ed. P. C. J. Kamer and P. W. N. M. van Leeuwen, John Wiley \& Sons, Ltd, Chichester, UK, 2012; (b) C. A. Tolman, Chem. Rev., 1977, 77, 313-348; (c) C. A. Fleckenstein and H. Plenio, Chem. Soc. Rev., 2010, 39, 694-711; (d) T. L. Brown and K. J. Lee, Coord. Chem. Rev., 1993, 128, 89-116; (e) M. L. Clarke and M. Heydt, Organometallics, 2005, 24, 6475-6478; ( $f$ ) A. Gómez-Suárez, D. J. Nelson and S. P. Nolan, Chem. Commun., 2017, 53, 2650-2660; (g) A. A. Oswald, D. E. Hendriksen, R. V. Kastrup, K. Irikura, E. J. Mozeleski and D. A. Young, Phosphorous Sulfur Relat. Elem., 1987, 30, 237-240; (h) S. Würtz and F. Glorius, Acc. Chem. Res., 2008, 41, 15231533; (i) R. F. Heck, Acc. Chem. Res., 1979, 12, 146-151; (j) H. M. L. Davies and D. Morton, Chem. Soc. Rev., 2011, 40, 1857-1859.

3 (a) L. A. van der Veen, M. D. K. Boele, F. R. Bregman, P. C. J. Kamer, P. W. N. M. van Leeuwen, K. Goubitz, J. Fraanje, H. Schenk and C. Bo, J. Am. Chem. Soc., 1998, 120, 11616-11626; (b) M. L. Clarke and J. J. R. Frew, in Organometallic Chemistry, The Royal Society of Chemistry, Cambridge, 2009, vol. 35, pp. 19-46; (c) D. J. Gorin, B. D. Sherry and F. D. Toste, Chem. Rev., 2008, 108, 33513378; (d) J. F. Hartwig, Inorg. Chem., 2007, 46, 1936-1947; (e) R. Burch, Acc. Chem. Res., 1982, 15, 24-31.

4 (a) P. W. N. M. van Leeuwen, P. C. J. Kamer, J. N. H. Reek and P. Dierkes, Chem. Rev., 2000, 100, 2741-2770; (b) L. A. van der Veen, P. C. J. Kamer and P. W. N. M. van Leeuwen, CATTECH, 2002, 6, 116-120; (c) P. W. N. M. van Leeuwen, P. C. J. Kamer, L. A. van der Veen and J. N. H. Reek, Chin. J. Chem., 2001, 19, 1-8; (d) M.-N. Birkholz, Z. Freixa and P. W. N. M. van Leeuwen, Chem. Soc. Rev., 2009, 38, 1099-1118; (e) P. C. J. Kamer, P. W. N. M. Van Leeuwen and J. N. H. Reek, Acc. Chem. Res., 2001, 34, 895-904.

5 For some general papers on regulation of proteins see: $(a)$ I. Bahar, C. Chennubhotla and D. Tobi, Curr. Opin. Struct. Biol., 2007, 17, 633-640; (b) J. H. Shi, J. Sivaraman and J. X. Song, J. Virol., 2008, 82, 4620-4629; (c) S. Raboni, S. Bettati and A. Mozzarelli, Cell. Mol. Life Sci., 2009, 66, 2391-2403; (d) N. J. Marianayagam, M. Sunde and J. M. Matthews, Trends Biochem. Sci., 2004, 29, 618-625; (e) E. U. Woehl and M. F. Dunn, Coord. Chem. Rev., 1995, 144, 147-197; (f) T. H. Kim, P. Mehrabi, Z. Ren, A. Sljoka, C. Ing, A. Bezginov, L. Ye, R. Pomès, R. Scott Prosser and E. F. Pai, Science, 2017, 355, eaag2355; $(g)$ R. L. Stein, in Kinetics of Enzyme Action, John Wiley \& Sons, Inc., Hoboken, NJ, USA, 2011, vol. 2, pp. 199-217; (h) S. D. Copley, in Comprehensive Natural Products II, Elsevier, 2010, pp. 9-46; ( $i$ ) N. F. König and N. Kulak, in Reference Module in Chemistry, Molecular Sciences and Chemical Engineering, Elsevier, 2015, pp. 1-15; (j) B. Nagel, H. Dellweg and L. M. Gierasch, Pure Appl. Chem., 1992, 64, 143-168. 
6 (a) N. Busschaert, C. Caltagirone, W. Van Rossom and P. A. Gale, Chem. Rev., 2015, 115, 8038-8155; (b) P. Dydio, D. Lichosyt and J. Jurczak, Chem. Soc. Rev., 2011, 40, 29712985; (c) R. Chakrabarty, P. S. Mukherjee and P. J. Stang, Chem. Rev., 2011, 111, 6810-6918; (d) N. H. Evans and P. D. Beer, Angew. Chem., Int. Ed., 2014, 53, 11716-11754; (e) L. Kovbasyuk and R. Krämer, Chem. Rev., 2004, 104, 3161-3188.

7 For reviews see: (a) D. L. Caulder and K. N. Raymond, Acc. Chem. Res., 1999, 32, 975-982; (b) A. V Davis, R. M. Yeh and K. N. Raymond, Proc. Natl. Acad. Sci. U. S. A., 2002, 99, 4793-4796; (c) A. J. McConnell, C. S. Wood, P. P. Neelakandan and J. R. Nitschke, Chem. Rev., 2015, 115, 7729-7793; (d) D. A. Roberts, B. S. Pilgrim and J. R. Nitschke, Chem. Soc. Rev., 2018, 47, 626-644; (e) A. M. Castilla, W. J. Ramsay and J. R. Nitschke, Acc. Chem. Res., 2014, 47, 2063-2073; (f) T. R. Cook and P. J. Stang, Chem. Rev., 2015, 115, 7001-7045; (g) M. Fujita, M. Tominaga, A. Hori and B. Therrien, Acc. Chem. Res., 2005, 38, 369-378.

8 For reviews and selected contributions: (a) V. Blanco, D. A. Leigh and V. Marcos, Chem. Soc. Rev., 2015, 44, 53415370; (b) E. R. Kay and D. A. Leigh, Angew. Chem., Int. Ed., 2015, 54, 10080-10088; (c) W. R. Browne and B. L. Feringa, Nat. Nanotechnol., 2006, 1, 25-35; (d) R. S. Forgan, J. P. Sauvage and J. F. Stoddart, Chem. Rev., 2011, 111, 5434-5464; (e) B. L. Feringa, J. Org. Chem., 2007, 72, 66356652; $(f)$ K. Kinbara and T. Aida, Chem. Rev., 2005, 105, 1377-1400; $(g)$ S. F. M. van Dongen, S. Cantekin, J. A. A. W. Elemans, A. E. Rowan and R. J. M. Nolte, Chem. Soc. Rev., 2014, 43, 99-122; (h) C. J. Bruns and J. F. Stoddart, Acc. Chem. Res., 2014, 47, 2186-2199; (i) A. Coskun, M. Banaszak, R. D. Astumian, J. F. Stoddart and B. A. Grzybowski, Chem. Soc. Rev., 2012, 41, 19-30; (j) D. A. Leigh, J. K. Y. Wong, F. Dehez and F. Zerbetto, Nature, 2003, 424, 174-179.

9 For reviews and selected contributions, see: (a) M. Raynal, P. Ballester, A. Vidal-Ferran and P. W. N. M. van Leeuwen, Chem. Soc. Rev., 2014, 43, 1734-1787; (b) M. Vaquero, L. Rovira and A. Vidal-Ferran, Chem. Commun., 2016, 52, 11038-11051; (c) J. Meeuwissen and J. N. H. Reek, Nat. Chem., 2010, 2, 615-621; (d) P. Dydio and J. N. H. Reek, Chem. Sci., 2014, 5, 2135-2145; (e) H. J. Davis and R. J. Phipps, Chem. Sci., 2017, 8, 864-877; (f) S. S. Nurttila, P. R. Linnebank, T. Krachko and J. N. H. Reek, ACS Catal., 2018, 8, 3469-3488; (g) E. Lindbäck, S. Dawaigher and K. Warmark, Chem.-Eur. J., 2014, 20, 13332-13481; (h) S. Das, C. D. Incarvito, R. H. Crabtree and G. W. Brudvig, Science, 2006, 312, 1941-1943; ( $i$ ) A. Bauer, F. Westkämper, S. Grimme and T. Bach, Nature, 2005, 436, 1139-1140; (j) S. C. Coote and T. Bach, J. Am. Chem. Soc., 2013, 135, 14948-14951; (k) T. Šmejkal and B. Breit, Angew. Chem., Int. Ed., 2008, 47, 3946-3949; (l) L. J. Jongkind, X. Caumes, A. P. T. Hartendorp and J. N. H. Reek, Acc. Chem. Res., 2018, 51, 2115-2128.

10 (a) C. G. Oliveri, P. A. Ulmann, M. J. Wiester and C. A. Mirkin, Acc. Chem. Res., 2008, 41, 1618-1629; (b) N. C. Gianneschi,
M. S. Masar and C. A. Mirkin, Acc. Chem. Res., 2005, 38, 825-837; (c) H. J. Yoon, J. Kuwabara, J.-H. Kim and C. A. Mirkin, Science, 2010, 330, 66-69; (d) I. O. Fritsky, R. Ott, H. Pritzkow and R. Krämer, Chem.-Eur. J., 2001, 7, 1221-1231; (e) I. O. Fritsky, R. Ott and R. Krämer, Angew. Chem., Int. Ed., 2000, 39, 3255-3258; (f) N. C. Gianneschi, P. A. Bertin, S. T. Nguyen, C. A. Mirkin, L. N. Zakharov and A. L. Rheingold, J. Am. Chem. Soc., 2003, 125, 10508-10509; (g) N. C. Gianneschi, S. T. Nguyen and C. A. Mirkin, J. Am. Chem. Soc., 2005, 127, 1644-1645; (h) M. S. Masar, N. C. Gianneschi, C. G. Oliveri, C. L. Stern, S. T. Nguyen and C. A. Mirkin, J. Am. Chem. Soc., 2007, 129, 10149-10158.

11 For contributions in effector controlled switch on/of (enantioselective/encapsulation) transition metal catalysis, see: (a) M. Vaquero, L. Rovira and A. Vidal-Ferran, Chem. Commun., 2016, 52, 11038-11051; (b) G.-H. Ouyang, Y.-M. He, Y. Li, J.-F. Xiang and Q.-H. Fan, Angew. Chem., Int. Ed., 2015, 54, 4334-4337; (c) I. Mon, D. A. Jose and A. Vidal-Ferran, Chem.-Eur. J., 2013, 19, 2720-2725; (d) L. Rovira, H. Fernández-Pérez and A. Vidal-Ferran, Organometallics, 2016, 35, 528-533; (e) L. J. Jongkind, J. A. A. W. Elemans and J. N. H. Reek, Angew. Chem., Int. Ed., 2019, 58, 2696-2699; ( $f$ ) P. Dydio, C. Ruby, T. Gadzikwa, M. Lutz and J. N. H. Reek, J. Am. Chem. Soc., 2011, 133, 17176-14179; $(g)$ L. Théveau, R. Bellini, P. Dydio, Z. Szabo, A. van der Werf, R. Afshin Sander, J. N. H. Reek, C. Moberg, L. T. Théveau, R. Bellini, P. Dydio, Z. Szabo, A. Van Der Werf, R. A. Sander, J. N. H. Reek and C. Moberg, Organometallics, 2016, 35, 1956-1963; (h) P. W. N. M. van Leeuwen, D. Rivillo, M. Raynal and Z. Freixa, J. Am. Chem. Soc., 2011, 133, 18562-18565; (i) A. C. H. Jans, A. Gómez-Suárez, S. P. Nolan and J. N. H. Reek, Chem.-Eur. J., 2016, 22, 14836-14939.

12 (a) P. Dydio and J. N. H. Reek, Angew. Chem., Int. Ed., 2013, 52, 3878-3882; (b) P. Dydio, R. J. Detz and J. N. H. Reek, J. Am. Chem. Soc., 2013, 135, 10817-10828; (c) P. Dydio, W. I. Dzik, M. Lutz, B. de Bruin and J. N. H. Reek, Angew. Chem., Int. Ed., 2011, 50, 396-400; (d) P. Dydio, R. J. Detz, B. de Bruin and J. N. H. Reek, J. Am. Chem. Soc., 2014, 136, 8418-8429.

13 C. S. Johnson, Prog. Nucl. Magn. Reson. Spectrosc., 1999, 34, 203-256.

14 Acetic acid was deprotonated by acac and the Hacac was observed by ${ }^{1} \mathrm{H}$ NMR at ca. $15 \mathrm{pmm}$ when mixing $\left[\mathrm{Rh}\left(\right.\right.$ acac) $\left.(\mathrm{CO})_{2}\right], \mathbf{L} 2$ and acetic acid in $\mathrm{CD}_{2} \mathrm{Cl}_{2}$.

15 S. H. Chikkali, J. I. van der Vlugt and J. N. H. H. Reek, Coord. Chem. Rev., 2014, 262, 1-15.

16 J. E. Del Bene, S. A. Perera and R. J. Bartlett, J. Phys. Chem. A, 1999, 103, 8121-8124.

17 Experimentally, we observe IR bands shifts when changing the apical $\mathrm{H}$ to D. Compared with HPIR spectra using $\mathrm{H}_{2}$ / CO, the IR bands $2062 \mathrm{~cm}^{-1}$ and $1982 \mathrm{~cm}^{-1}$ of the Rh-CO absorption shift to the low frequency region $2040 \mathrm{~cm}^{-1}$ and $1967 \mathrm{~cm}^{-1}$ with 22 and $15 \mathrm{~cm}^{-1}$, respectively, upon performing HPIR experiment using $\mathrm{D}_{2} / \mathrm{CO}$. 
18 The minor active species is identified by ${ }^{1} \mathrm{H}$ NMR. According to DOSY spectra, the diffusion constant is comparable to the monomeric species $\left[\mathrm{Rh}(\mathbf{L 1})(\mathrm{CO})_{2} \mathrm{H}\right]$, indicating a monomeric structure. Unfortunately, the phosphorus NMR signals is not identified for this species. Noted that it needs four days of acquisition to obtain phosphorus NMR spectra with satisfactory signal-to-noise ratio for the monomeric species with effector binding to the DIM-receptor. It suggest that even longer time needed to obtain the phosphorus signals for such small amounts of species.

19 For typical metal-carbonyl species IR bands, see: (a) Y. S. Varshavskii, T. G. Cherkasova, I. S. Podkorytov, A. A. Korlyukov, V. N. Khrustalev and A. B. Nikol'skii, Russ. J. Coord. Chem., 2005, 31, 121-131; (b) D. Evans, J. A. Osborn and G. Wilkinson, J. Chem. Soc. A, 1968, 31333142; (c) K. Nozaki, T. Matsuo, F. Shibahara and T. Hiyama, Organometallics, 2003, 22, 594-600.

20 For theory of DFT calculations on the metal-carbonyl IR bands, see: (a) P. Deglmann and F. Furche, J. Chem. Phys., 2002, 117, 9535-9538; (b) P. Deglmann, F. Furche and R. Ahlrichs, Chem. Phys. Lett., 2002, 362, 511-518.

21 For theory of DFT calculations on phosphorus chemicals shifts and coupling constants, see: (a) M. Kollwitz and J. Gauss, Chem. Phys. Lett., 1996, 260, 639-646; (b) S. K. Wolff and T. Ziegler, J. Chem. Phys., 1998, 109, 895905; (c) G. Schreckenbach and T. Ziegler, J. Phys. Chem., 1995, 99, 606-611.
22 DFT calculations show that the monomeric species with effector binding to the DIM-receptor is much more stable than the dimeric conformers. However, experimentally we need adequate amounts of effectors to drive this process. On one hand, the effectors generated are also under equilibrium and thus the concentration of the carboxylate anions might be not that high as the input. On the other hand, HP IR titration experiments indeed confirm that the effector binding to the DIM-receptor is the driving force for converting the dimeric to monomeric species. We also tried to use tetrabutylammonium acetate as the effector to regulate the equilibrium. Unfortunately, we did not observe the expected IR band at $1902 \mathrm{~cm}^{-1}$ and also no aldehydes were detected when adding substrate into the autoclave. These failed experiments suggest that the strong acetate anions or the tetrabutylammonium salts might inhibit the active species formation.

23 (a) S. H. A. M. Leenders, R. Gramage-Doria, B. de Bruin and J. N. H. Reek, Chem. Soc. Rev., 2015, 44, 433-448; (b) Q.-Q. Wang, S. Gonell, S. H. A. M. Leenders, M. Dürr, I. Ivanović-Burmazović and J. N. H. Reek, Nat. Chem., 2016, 8, 225-230.

24 (a) M. Kranenburg, Y. E. M. van der Burgt, P. C. J. Kamer, P. W. N. M. van Leeuwen, K. Goubitz and J. Fraanje, Organometallics, 1995, 14, 3081-3089; (b) Z. Freixa and P. W. N. M. van Leeuwen, Dalton Trans., 2003, 1890-1901. 